\title{
Life history and zonation dynamics of the cirolanid isopod, Eurydice nipponica Bruce \& Jones, on an intertidal sandflat in western Kyushu, Japan
}

\section{Akio Tamaki and Kenji Suzukawa}

Abstract. - A dense population of the cirolanid isopod, Eurydice nipponica Bruce \& Jones, inhabited an intertidal sandflat in western Kyushu, Japan. Newly-ovigerous female groups occurred twice yearly, during March to June and August to October, generating two major recruitment groups: June to July (summer group) and September to November (autumn group). The summer group became ovigerous after 2 mo, with most of the early recruits to the group dying out after breeding (3-5-mo life span). Some of the later summer recruits overwintered to have their second brood, dying out during spring to summer. Members of the autumn group overwintered to have their first brood during late spring to mid-summer, some of them surviving longer to have their second brood just before dying (12-13-mo life span). The life history pattern for males was not as clear as for females owing to the successive merging of the newly-recruited individuals into the older ones with smaller asymptote body sizes. The center of distribution of the population along the elevation gradient on the sandflat was generally located around the MLWS level, with the breeding components mostly concentrated there. Most probably part of the overwintering population migrates to the subtidal zone to avoid the harsh conditions of the winter months.

\section{Introduction}

Cirolanid isopods are one of the com- monest macroinvertebrate members in open (exposed) marine beaches worldwide (e.g., Dahl, 1952; McLachlan \& Jaramillo, 1995), and presumably play significant roles in both the community organization and the ecosystem dynamics (e.g., Brown \& McLachlan, 1990). Of this family, several ecological aspects of species of the genus Eurydice have been well studied, especially their circa-tidal/circadian/circa-semilunar behavioral rhythmicities (e.g., Jones \& Hobbins, 1985) and their distribution patterns along the elevation gradient of beaches (e.g., McLachlan \& Jaramillo, 1995; Raffaelli \& Hawkins, 1996). In contrast, the number of studies on their life histories is quite limited [E. pulchra Leach - Salvat, 1966; Jones, 1970; Fish, 1970; $E$. affinis Hansen - Salvat, 1966; Jones, 1970; E. longicornis (Stüder) - De Ruyck et al., 1991]. Scarcity of information on life history and population dynamics is also a bottleneck for the development of community and ecosystem studies.

For an intertidal sandflat in western Kyushu Island, Japan, Tamaki \& Suzukawa (1991) described a high-density (mean: about $360 \mathrm{~m}^{-2}$ ) population of $E u$ rydice nipponica Bruce \& Jones. Mean densities found there are higher than those collected from an open sandy beach in Kyushu Island [mean: up to $40 \mathrm{~m}^{-2}$ (Jones \& Hobbins, 1985)]. The sandflat is moderately protected from prevailing winds (Tamaki, 1984, 1987), which is rather an atypical habitat for $E$. nipponica (Bruce \& Jones, 1981; Jones \& 
Hobbins, 1985). Tamaki \& Suzukawa (1991) ascribed the presence of the large population of $E$. nipponica on the sandflat to its co-occurrence with the callianassid ghost shrimp, Callianassa japonica Ortmann (Decapoda: Thalassinidea); $C$. japonica, through its bioturbating activities, produced the sediment characteristics of the protected sandflat approximating those of the open sandy beaches which are the preferred habitat of $E$. nipponica (Bruce \& Jones, 1981; Jones \& Hobbins, 1985). However, investigation of the life history pattern of the $E$. nipponica population on the sandflat has not yet been undertaken. The first purpose of this paper is to reveal various aspects associated with the life history of $E$. nipponica based on a one-year survey and to compare them with other studies of Eurydice species. The second purpose is to describe the seasonal change in zonation on the sandflat, especially in relation to the breeding and recruitment events.

\section{Materials and Methods}

\section{Study area and organisms}

The following summary is mostly based on the description in Tamaki \& Suzukawa (1991) and Tamaki et al. (1997). The study area is an intertidal sandflat situated on the northwestern corner of AmakusaShimoshima Island $\left(130^{\circ} 02\right.$ 'E; $\left.32^{\circ} 31^{\prime} \mathrm{N}\right)$, western Kyushu, Japan (Fig. 1). The sandflat faces Tomioka Bay in the westernmost part of Ariake Sound, and extends about $4 \mathrm{~km}$ along the shoreline, where it is exposed for 150 to $700 \mathrm{~m}$ seaward at extreme low water spring tide. On the transect used for the sampling of Eurydice nipponica (see the next section; Fig. 1), the extreme low water spring tide (ELWS) level, the mean low water spring tide (MLWS) level, and the mean low water neap tide (MLWN) level (= close to the highest elevation of the sandflat) were situated $335 \mathrm{~m}, 310 \mathrm{~m}$, and $160 \mathrm{~m}$ from the high water mark (hereafter simply

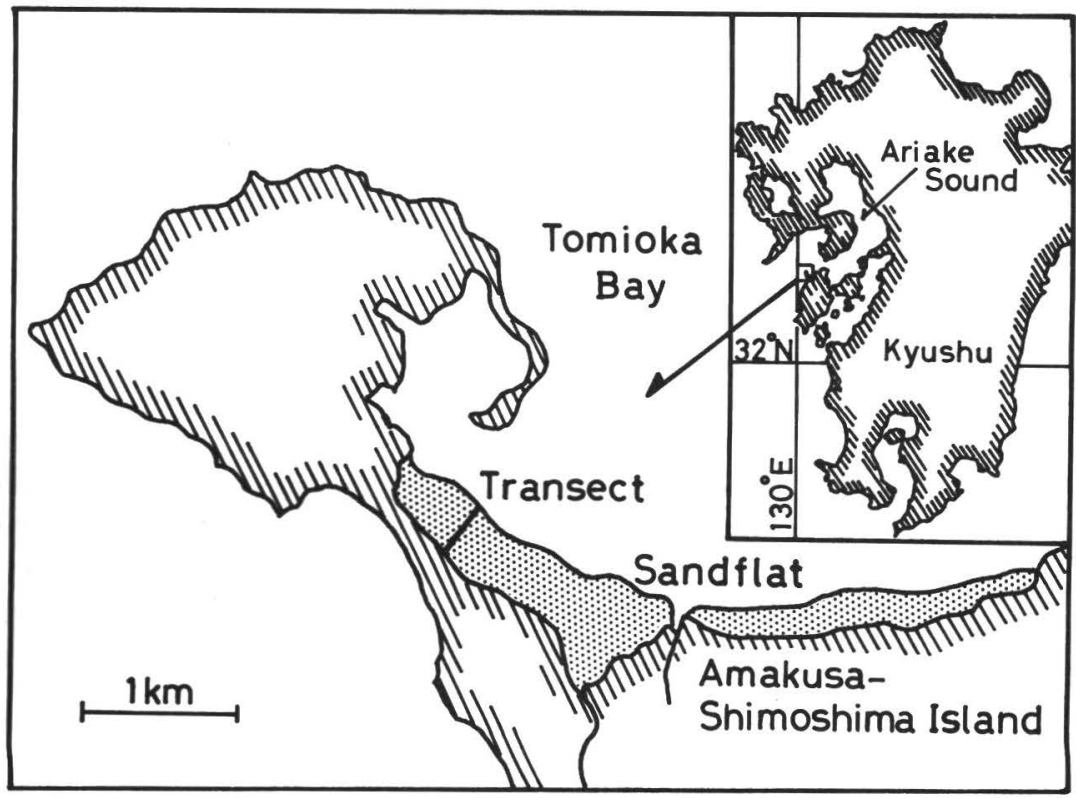

Fig. 1. Location of the transect for sampling Eurydice nipponica on the Tomioka Bay sandflat (dotted area), western Kyushu. 


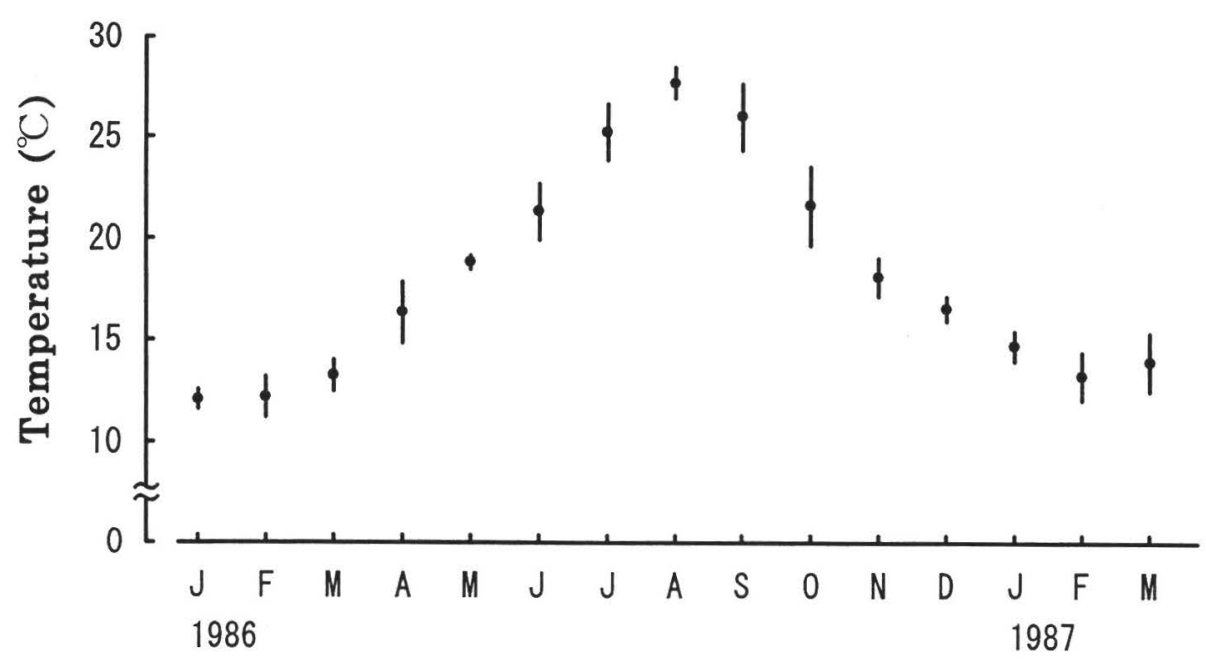

Fig. 2. Monthly mean \pm SD temperature of the surface waters measured about $1 \mathrm{~km}$ from the study area during January 1986 to March 1987 (number of the measurement per month =1723). From Goto \& Kikuchi (unpublished).

referred to as the shore), respectively. The maximum depth of the water column that covers the sandflat at spring high tides is $3.3 \mathrm{~m}$. The sediment of the sandflat is of well to moderately sorted, fine sand, with the silt-clay content lower than $2.6 \%$. Both E. nipponica and Callianassa japonica are distributed over almost the entire sandflat, with their densities varying parallel to the shoreline (i.e., zoned patterns). In the sediment column, all individuals of $E$. nipponica can be found in the upper $15-\mathrm{cm}$ and $67-79 \%$ of these are distributed in the first $10-\mathrm{cm}$ portion.

The water temperature of the sea surface was measured in the vicinity of the study area (about $1 \mathrm{~km}$ away) on a daily basis for at least $17 \mathrm{~d}$ per month (Goto \& Kikuchi, unpublished). During the entire period (January 1986 - March 1987), the monthly average water temperature ranged between $12.1^{\circ} \mathrm{C}$ (January 1986) and $27.7^{\circ} \mathrm{C}$ (August 1986) (Fig. 2). The monthly averaged salinity values were between 32.5\%o (August 1986) and 34.5\%o (February 1986) (Goto \& Kikuchi, pers. comm.).

\section{Field sampling}

Sampling of the Eurydice nipponica population was conducted on a total of 13 occasions (spring tides) during January 1986 to March 1987, with an interval of 2 wk to 2.5 mo (indicated in Fig. 3). The stations for the collection were placed along a transect perpendicular to the shoreline, with the most landward station being $10 \mathrm{~m}$ from the shore (Fig. 1). Hereafter $\mathrm{Stn} \mathrm{X}$ denotes a station which is $\mathrm{X} \mathrm{m}$ distant from the shore. From Stn 20 to Stn 300,15 stations were established at 20-m intervals; beyond Stn 300, three stations were established at 10-m intervals. The number of stations surveyed on each sampling occasion varied from 16 to 19 , most frequently 18 , except for 20 July 1986 when only three stations were visited. During low tide on these occasions (except 20 July 1986), most of the samples were collected by excavating the sediment within a $25 \times 25-\mathrm{cm}$ quadrat frame to a depth of $10 \mathrm{~cm}$ and sieving it through a $0.5-\mathrm{mm}$ mesh sieve. The retained material was fixed with $10 \%$ neutralized formalin solution. The number $(n)$ of quadrat 
samples at each station was one except for ten cases indicated in Fig. 8, where $n$ varied from 2 to 7 . The lowermost three stations were not always exposed even during the lowest tide; in such (11) cases indicated in Fig. 8, six 100- $\mathrm{cm}^{2}$ (cross sectional area) $\times 10-\mathrm{cm}$ long sediment columns were collected by a $100-\mathrm{cm}^{2} \times 50-\mathrm{cm}$ acrylic tube and combined as a substitute for one quadrat $\left(625-\mathrm{cm}^{2}\right)$ sample. On 20 July 1986, samples which covered the entire sediment column [about 25 to $40 \mathrm{~cm}$ in length (Tamaki \& Suzukawa, 1991)] were collected with the use of the acrylic tube mentioned above at $\operatorname{Stn} 60(n=16)$, Stn $160(n=14)$, and Stn $260(n=12)$. Each sample was separately sieved and fixed.

\section{Laboratory treatment and data analysis}

In the laboratory, individuals of Eurydice nipponica were sorted out from the sieved samples and the sex was initially determined according to the following criteria: ovigerous females are recognized by the conspicuous presence of ovaries, eggs, or embryos (obs: E. nipponica females incubate embryos in their internal brood pouches); and males are distinguished from non-ovigerous females by having a pair of appendix masculina on pleopods 2 (the presence or absence of penes was also used as a subsidiary key feature). The developmental stages of ovaries, eggs, or embryos held by each ovigerous female were categorized into four "egg" stages according to the following characters (apparently, the stage was the same in a single ovigerous female). Egg Stage I= Unfertilized eggs in the ovaries, recognized as either a continuous yellow-colored material (yolk mass) or subdivided matter; in the latter case, each subdivision is an angular-shaped piece with its surface easily collapsed with, for example, a forceps. Egg Stage II = Recently fertilized eggs (ova), slightly elliptical ball-shaped structure with its surface enveloped by a supple egg membrane.
Egg Stage III = Embryos enveloped by an embryonic membrane, undergoing both eye and limb formation; as the pigmentation of eyes proceeds, the dorsal surface of the body is stippled with black stellate chromatophores. Egg Stage IV = Embryos, with their embryonic membrane ruptured; finally at this stage, the body morphology is indistinguishable from that of the first free-living mancas collected in the field. To determine the clutch size, the number of eggs (embryos) held by each female was counted by each egg stage for the specimens collected on 10 May and 4 September 1986. Furthermore, to determine the dimensions of Stage II eggs of these specimens, five eggs were randomly selected from each female. Assuming each egg to be an ellipsoid, the lengths of the major and minor axes were measured to the nearest $0.005 \mathrm{~mm}$ with an eyepiece micrometer of a microscope. The mean single egg volume (V) from each female was calculated from the formula, $\mathrm{V}=\pi(\mathrm{ma})(\mathrm{mi})^{2} / 6$, where (ma) and (mi) are the mean lengths of the major and minor axes of the eggs. Mancas which have just been released from ovigerous females do not possess pereopods 7 . When pereopods 7 first appear, they are folded toward and attached to the sternum. In due course, these pereopods become expanded normal to the sternum, at which time the presence of appendix masculinas is observed for some individuals (regarded as males) but not for the others (regarded as females). Of all collected animals there was only a single individual whose pereopods 7 were not fully expanded but pleopods 2 were already equipped with appendix masculinas. Thus those free-living mancas either lacking pereopods 7 or having them but in incompletely expanded conditions were regarded as sex-unidentified individuals (hereafter referred to as juveniles).

For each individual of Eurydice nipponica, the entire mid-dorsal line from the tip of the cephalon to the posterior margin 
of the telson was traced under a stereomicroscope fitted with a camera lucida (27.8 $\mathrm{x})$ and the total mid-dorsal length (TL) calculated to the nearest $0.1 \mathrm{~mm}$ for its body size. Body-size (TL)-frequency distributions were made separately for females and males for each sampling occasion, in which the data from all stations were pooled. Size-class interval was set at 0.23 $\mathrm{mm}$. Juveniles in each size class were allocated equally to both sexes. This is based on the nearly equal sex ratio recorded for the rest of the population. The analytical strategy of the TL-frequency distributions differed between sexes owing to the differences in their growth patterns and maximum body sizes. For females, each TL-frequency distribution was divided into multiple normal-distribution groups (cohorts) based on a computer program using Cassie's (1954) and Taylor's (1965) methods (Tsutsumi \& Tanaka, 1987). However, no curve fitting was made in the following three cases: 1) for a group comprising several possible cohorts, the total number of individuals was too few to be subdivided; 2) when sampling occurred during the process of population recruitment, the remaining group of the larger-sized cohorts isolated from an original TL-frequency distribution was not established as a newly-recruited cohort corresponding to a normal distribution (i.e., several smallest size classes representing a distribution with its left edge truncated); and 3) after recruitment with a fairly constant intensity had continued for an extended period, a resultant uniform TL-frequency distribution of several smallest size classes was not subdivided [in such a case, the total number of individuals was relatively small (see Fig. 3)]. In order to carry out further analyses, each of the above three groups was regarded as a cohort even when it might actually be composed of multiple cohorts: 1) the TL- "mode" of the cohort was operationally defined as the mid-point between both ends of the constituent size classes; and 2) the density of the cohort defined as the total number of individuals belonging to all these size classes. Based on the results of the cohort separation (indicated in Fig. 3), the life history pattern and breeding characteristics were examined. In particular, the growth curves were made by following the progresssion of the TL-modes of the (normal-) distributions of the corresponding cohorts through time. The survivorship curves were made by tracing the densities of the (normal-) distributions of the corresponding cohorts (converted to the values per $\mathrm{m}^{2}$ of the sandflat) through time. For males, it was observed that newly-recruited juveniles rapidly grew to merge into the previouslyrecruited groups and that the maximum, asymptote body sizes were much smaller than those of females. It was impractical, therefore, to separate multiple cohorts for most sampling occasions. Thus the growth was examined only by following the median TL of all individuals identified as males through time. The change in the density was inspected by tracking the total number of males through time.

To examine the spatial and temporal changes in the distributions of juveniles, males, and females along the transect, the densities of these three categories (all data normalized for those per $625 \mathrm{~cm}^{2}$ ) at each station were plotted for all sampling occasions.

\section{Results}

\section{Basic population characteristics}

In this section, several fundamental parameters of the Eurydice nipponica population are given, which are the basis for the description in subsequent sections.

A total of 4100 individuals were collected; 1310 females, 1419 males, and 1371 juveniles, giving a slightly malebiased sex ratio (1: 1.08).

The TL-frequency distributions for females and males are shown in Fig. 3. Multiple normal-distribution curves are 
$\square$ Juveniles Egg Stage I Egg Stage II
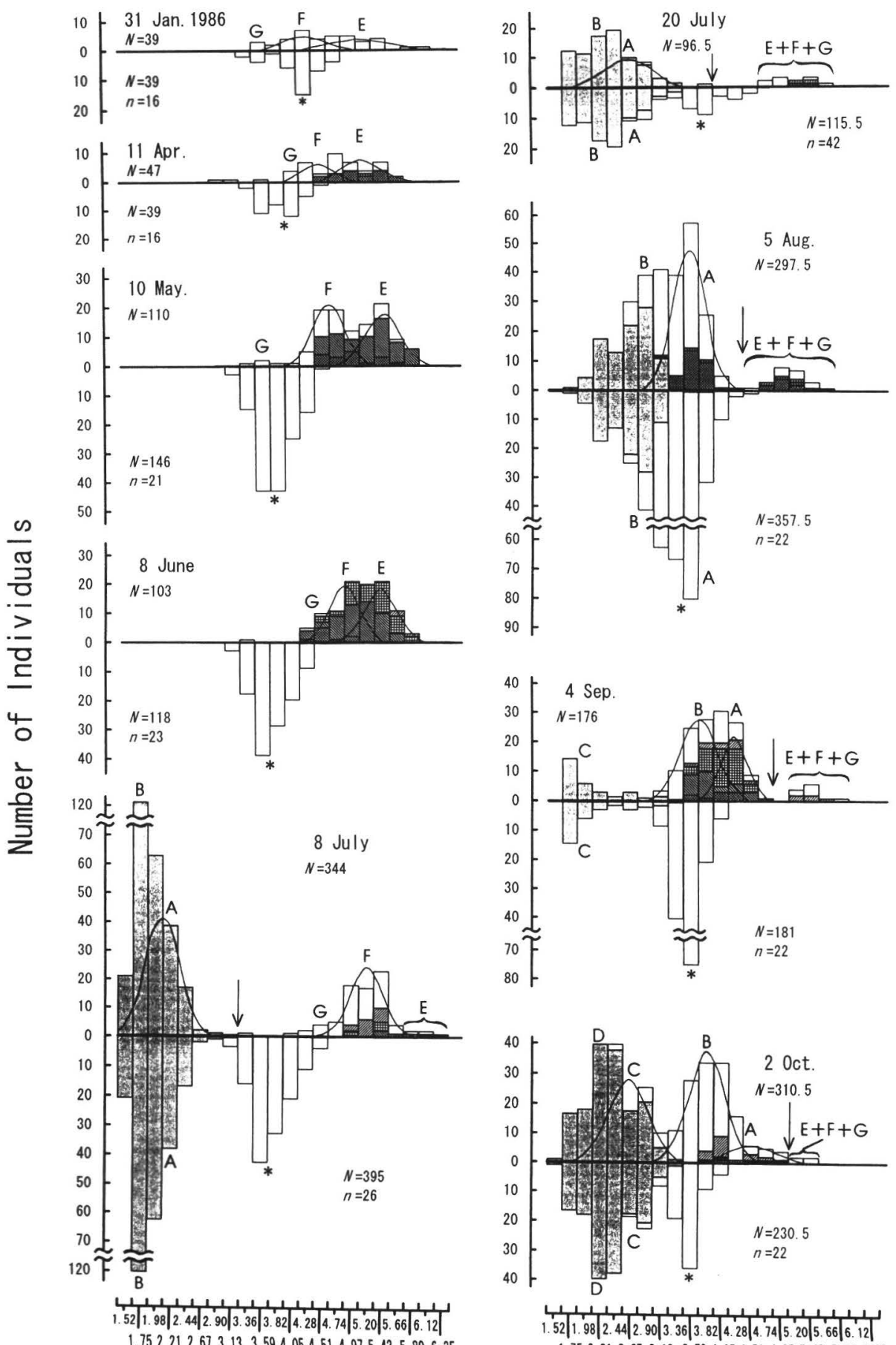

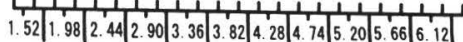
\begin{tabular}{l}
$1.752 .212 .673 .13 \quad 3.594 .054 .514 .975 .435 .896 .35$ \\
\hline
\end{tabular}

Total Length (mm) 


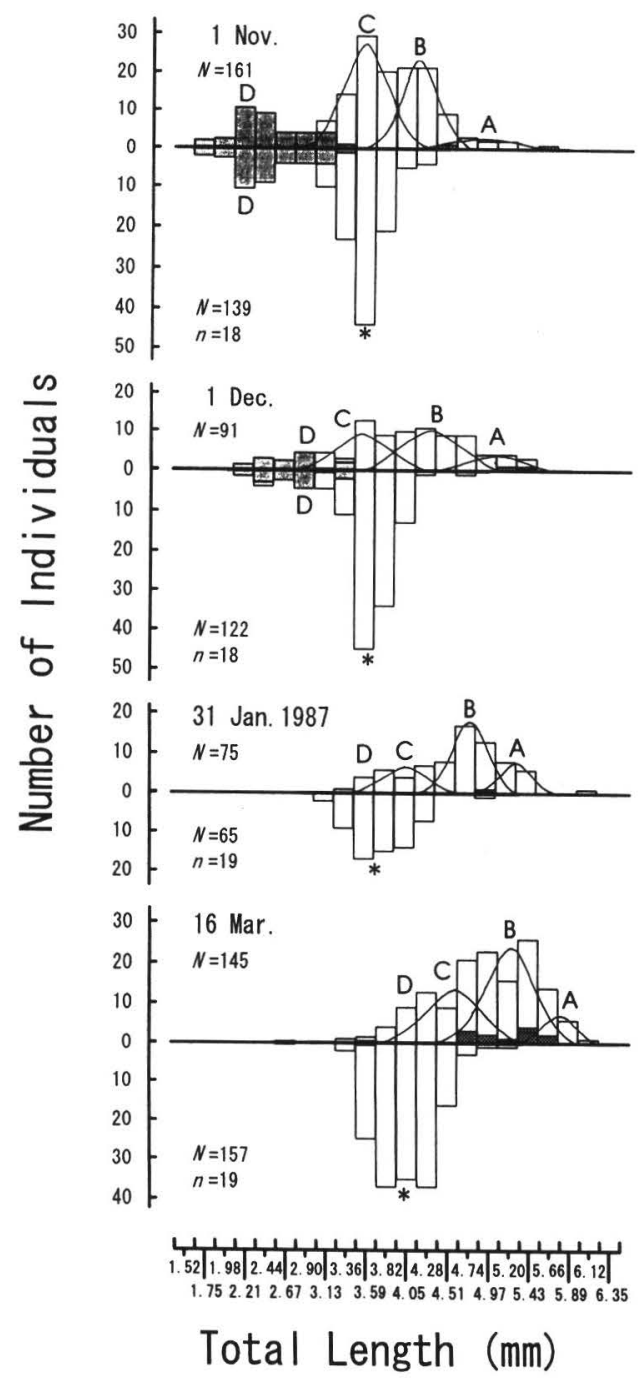

Fig. 3. Body size (TL)-frequency distributions for females (above on each date) and males (below) of Eurydice nipponica throughout the study period. Data from all stations are combined. Juveniles and ovigerous females with Egg Stages I-IV are expressed by different markings. Blank parts in females stand for non-ovigerous ones. Asterisk on each date indicates the median TL for all males (excluding juveniles). Cohorts are designated by $A$ to $G$, to some of which normaldistribution curves are fitted; no curve fitting is made to the other cohorts (see the first and second sections in Results). The arrow on each date during July to October 1986 indicates the boundary between the 1986-summer-recruitment group and the 1985-recruitment group in females (see text). $n$, number of quadrat (or core on 20 July 1986) samples including all replicates at several stations indicated in Fig. 8; $N$, total number of individuals of the isopod [the minimum unit is 0.5 because the number of juveniles in each size class was evenly allocated to both sexes (see text)]. 
superimposed on most of the figures for females. The rationale for the cohort separation is detailed in the next section. In 1986, ovigerous females were first found on 11 April (45\% of the females), whose eggs were all at Stage I except for the occurrence of a single female with Stage II eggs. In 1987, although a single ovigerous female with Stage I eggs was found on 31 January, a noticeable but still low proportion (8\%) of females with Stage I eggs (and a single female with Stage II eggs) appeared on 16 March. It is, therefore, suggested that ovary development in females started substantially from March to April each year, during which time a rapid increase in the seawater temperature occurred (by $3.1^{\circ} \mathrm{C}$ : Fig. 2). Of those females which had overwintered, the ovary development was first seen in the larger-sized individuals. During the earlier part of the breeding season of 1986 , the smallest ovigerous female with 4.3$\mathrm{mm}$ TL appeared on 8 June. The breeding season of 1986 seems to have almost terminated during October, although two ovigerous females were still present on both 1 November and 1 December.

In 1986, newly-recruited juveniles were first found on 8 July, with the smallest TL of $1.5 \mathrm{~mm}$, which were apparently derived from the ovigerous females on 8 June (Fig. 3). A large amount of recruitment ensued until 20 July, followed by a quite small one on 5 August. Hereafter, those juveniles recruited mainly during July 1986 [most probably, the recruitment had already started in June (see the next section)], is collectively referred to as the 1986-summer-recruitment group. On 20 July, sexes had become distinguishable in several larger-sized individuals of the group (though only a few in number), at the smallest TL of $2.7 \mathrm{~mm}$. Furthermore, as early as 5 August, a noticeable number of females of the group were ovigerous, at the smallest TL of $3.2 \mathrm{~mm}$. During 8 July to 2 October, the discrimination between the female 1986 -summer- recruitment group and the female group that had overwintered from 1985 could fairly obviously be made, their boundary on each date indicated by an arrow in Fig. 3. Ovigerous females of these two groups during 5 August to 2 October gave birth to juveniles recruited during 4 September to 1 November (hereafter referred to as the 1986-autumn-recruitment group). No recruitment occurred after 1 November. The female group that had overwintered from 1985 apparently disappeared between 2 October and 1 November. On 16 March 1987, the female 1986-summerand autumn-recruitment groups together constituted the TL-frequency distribution whose position and shape are similar to those exhibited by the females on 11 April and 10 May 1986 (though different in the numbers of individuals). Thus it would be reasonable to assume that the females occurring on 31 January 1986 had come from those juveniles recruited during the summer and autumn of 1985 (hereafter collectively referred to as the 1985recruitment group).

Figure 4-above and -below show the temporal changes in the proportion of ovigerous females with each of the four egg stages in the 1985-recruitment group and in the 1986-summer-recruitment group, respectively. In the 1985-recruitment group, there were two peaks for each egg stage. This clearly indicates that females of this group could brood twice through the breeding season. In the 1986summer-recruitment group, a single peak was recorded for each egg stage, indicating the group's participation in a single brooding event during the latter part of the breeding season. Each peak for Egg Stages II, III, and IV in this group lagged behind each second peak for these stages in the 1985-recruitment group by 1 mo, respectively. Apparently, the two major seasonal pulses in the egg production by the entire female population brought about the two discrete 1986-recruitment groups. If it is assumed that 1) Stage II 


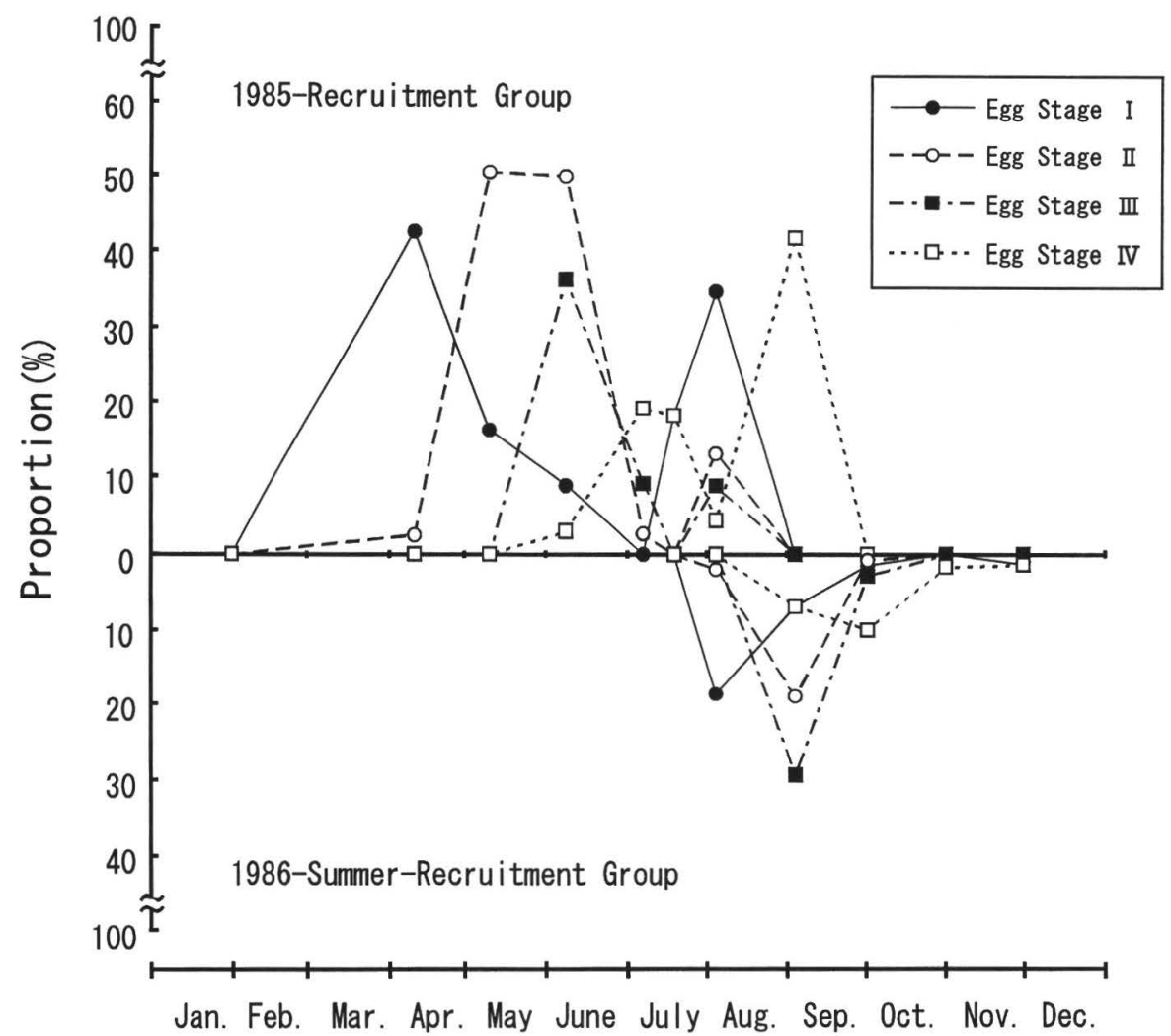

Fig. 4. Temporal changes in the proportion of ovigerous females of Eurydice nipponica with each of four egg stages in the 1985-recruitment group (above) and in the 1986-summer-recruitment group (below) during 1986. Based on Fig. 3, females with the following TL-class ranges are regarded as the entire population that could potentially be ovigerous: in the 1985-recruitment group-13 \& over (April to July); 14 \& over (August); and 17 \& over (September and October); in the 1986-summer-recruitment-group-8 to 13 (August); 8 to 15 (September); 8 to 16 (October); and 8 to 19 (November).

eggs emerged shortly after copulation and 2) the appearance of Stage IV eggs led to the imminent hatching of mancas from females, each corresponding peak-to-peak period between Stage II and Stage IV eggs gives an estimated brooding period of ca. 1.5-2 mo during spring to summer 1986 (for the first brood by the 1985-recruitment group) and ca. 1 mo during summer to autumn 1986 (for both the second brood by the 1985-recruitment group and the first brood by the 1986-summer-recruitment group), respectively.

Figure 5 illustrates the relationship between the number of Stage II eggs per female and the female's respective body size, expressed as TL cubed, for the 1985recruitment group (on 10 May 1986) and the 1986-summer-recruitment group (on 4 September 1986). The number of eggs per female was higher in the former group [mean \pm SD and range $(n=$ number of females) $-25.8 \pm 4.8$ and $14-39(n=53)$ vs. $8.5 \pm 3.0$ and $3-17(n=25)$ ], apparently reflecting the difference in the size of females (mean \pm SD TL: $5.2 \pm 0.4 \mathrm{~mm}$ vs. $4.0 \pm 0.3 \mathrm{~mm}$ ). The difference in the number of eggs per female corrected for body size between the two groups was tested (ANCOVA) using the SPSS statistical 


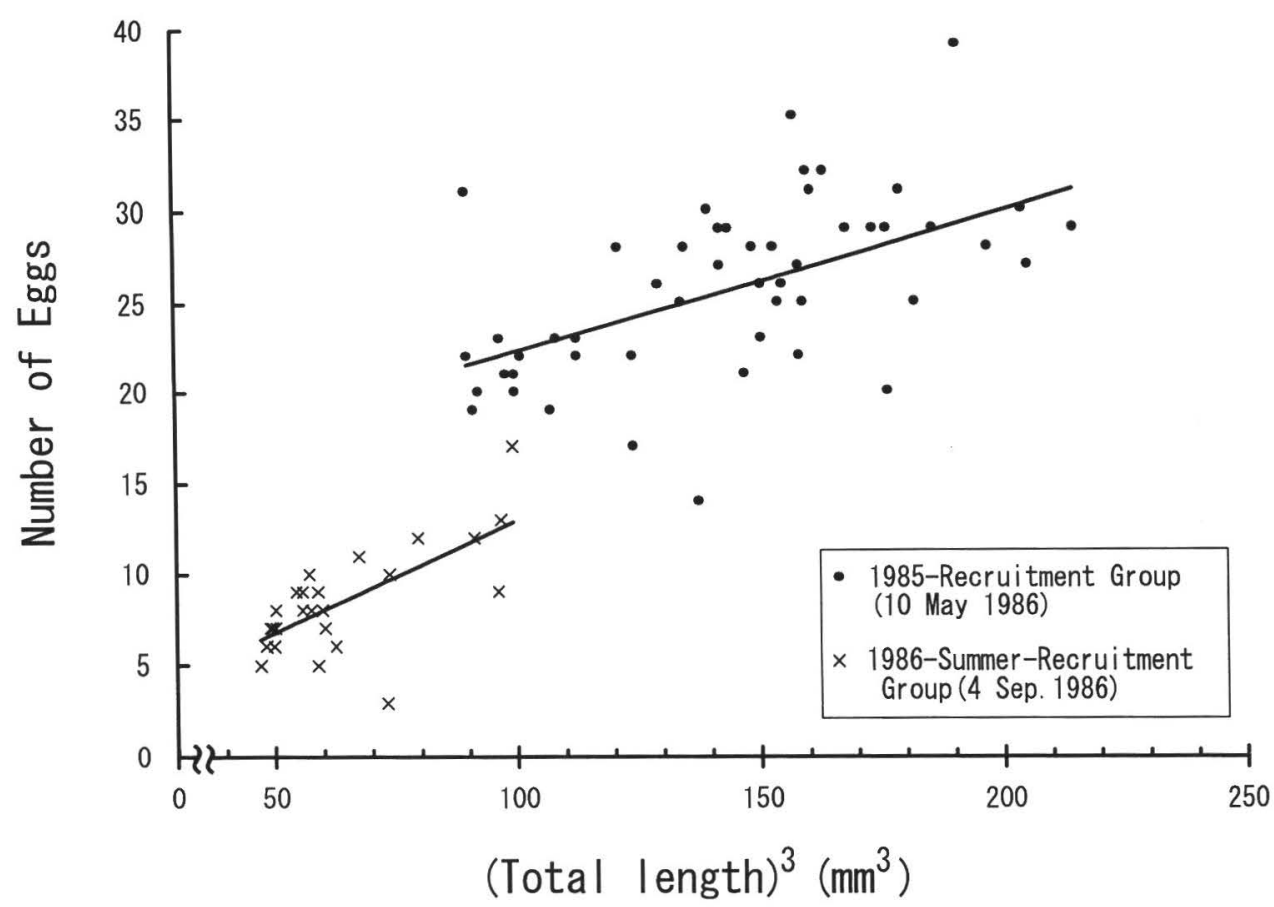

Fig. 5. Linear regression of the number of eggs per female on cubed TL for females with Stage II eggs of Eurydice nipponica from the 1985-recruitment group collected on 10 May 1986 [circles: No. of Eggs $\left.=0.0762 \mathrm{TL}^{3}+14.6548\left(n=53, r^{2}=0.32, P<0.001\right)\right]$ and from the 1986-summerrecruitment group collected on 4 September 1986 [crosses: No. of Eggs $=0.1248$ TL $^{3}+0.4839(n$ $\left.=25, r^{2}=0.48, P<0.001\right)$, respectively.

package (Norušis, 1994), and was highly significant $(P<0.001)$. The mean single egg volume from each female in the 1985recruitment group was slightly smaller than in the 1986-summer-recruitment group [mean $\pm \mathrm{SD}-0.022 \pm 0.003 \mathrm{~mm}^{3}$ $(n=53)$ vs. $\left.0.024 \pm 0.004 \mathrm{~mm}^{3}(n=25)\right]$, and the difference between the groups was significant ( $t$-test; $P<0.01$ ). The larger egg size in the latter group could cause a reduction of the egg number per female, but it would have been only by $10 \%$ if at all.

It is obvious from Fig. 3 that females grew much larger than males. For example, in the 1985-recruitment group during 10 May to 20 July 1986, the TLfrequency distributions of both sexes are clearly separated with only a little overlap. The maximum TLs for females and males recorded throughout the study period were 6.3 and $5.1 \mathrm{~mm}$, respectively. Following the summer-recruitment in June - July 1986, the body-size difference between sexes was becoming apparent as early as 4 September.

The temporal changes in the densities of juveniles, males, and females averaged over all stations throughout the study period is summarized in Fig. 6. The maximum total densities were recorded around the first (= summer) recruitment pulse in $1986\left(457.3-505.1 \mathrm{~m}^{-2}\right)$. Subsequently, the total density decreased on 4 September but increased to the second peak $\left(393.4 \mathrm{~m}^{-2}\right)$ on 2 October due to the second ( $=$ autumn) recruitment pulse in 1986 . The minimum total densities were recorded in winter and spring (78.0, 86.0, and 117.9 $\mathrm{m}^{-2}$ on 31 January, 11 April 1986, and 31 January 1987, respectively). Following these minima, however, the density for 


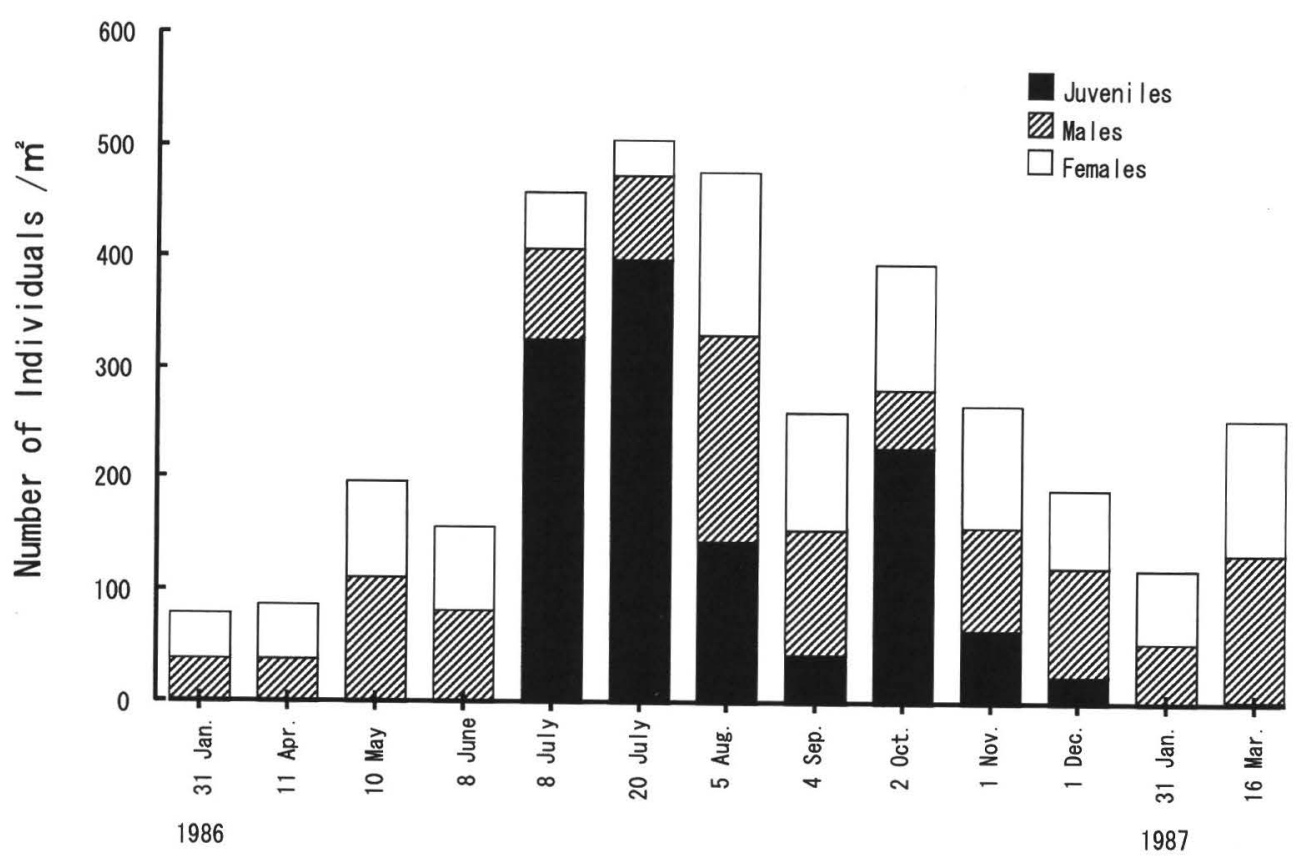

Fig. 6. Temporal changes in the densities of juveniles, males, and females of Eurydice nipponica averaged over all stations during the study period.

each sex increased considerably to that on 10 May 1986 and to that on 16 March 1987 , respectively, regardless of the period concerned being the non-recruitment season.

Cohort separation, survival, and growth in females

In females, each of the two recruitment groups in 1986 can be subdivided into two cohorts, designated as Cohorts A $\& \mathrm{~B}$ and Cohorts $\mathrm{C} \& \mathrm{D}$, respectively in Fig. 3. The recruitment to Cohort A should have actually started during June, because 1) Stage IV eggs observed in the 1985-recruitment group were found on 8 June and 2) on 8 July, the cohort had been established as a normal-distribution group. The recruitment to Cohort B was progressing on 8 July and ended on 20 July. On 5 August, a noticeable portion (25\%) of Cohort A carried Stage I and II eggs. These were, together with those of the 1985-recruitment group, the sources for the newly-recruited juveniles on 4
September (Cohort C). Cohort C was established as a normally distributed group by 2 October. On 4 September, a considerable portion (62\%) of Cohorts A and $\mathrm{B}$, as well as that of the last remainder of the 1985-recruitment group (42\%), were ovigerous, giving birth to Cohort D on 2 October. The proportional contribution to Cohort D by Cohorts (A+B) relative to that by the 1985-recruitment group assessed in terms of their total numbers of eggs plus embryos was much higher (609 vs. 83). On 1 November, Cohort D was recognized as an elongate distribution group with a large variance around the mode, most of which still remained juveniles probably due to their slower growth rates in response to the decreasing seawater temperatures (Fig. 2). Apparently, neither Cohort C nor Cohort $\mathrm{D}$ became ovigerous until the last sampling occasion (16 March 1987), when all four cohorts had overwintered.

Based on the above cohort separation, Fig. 7-above and -below illustrate the 

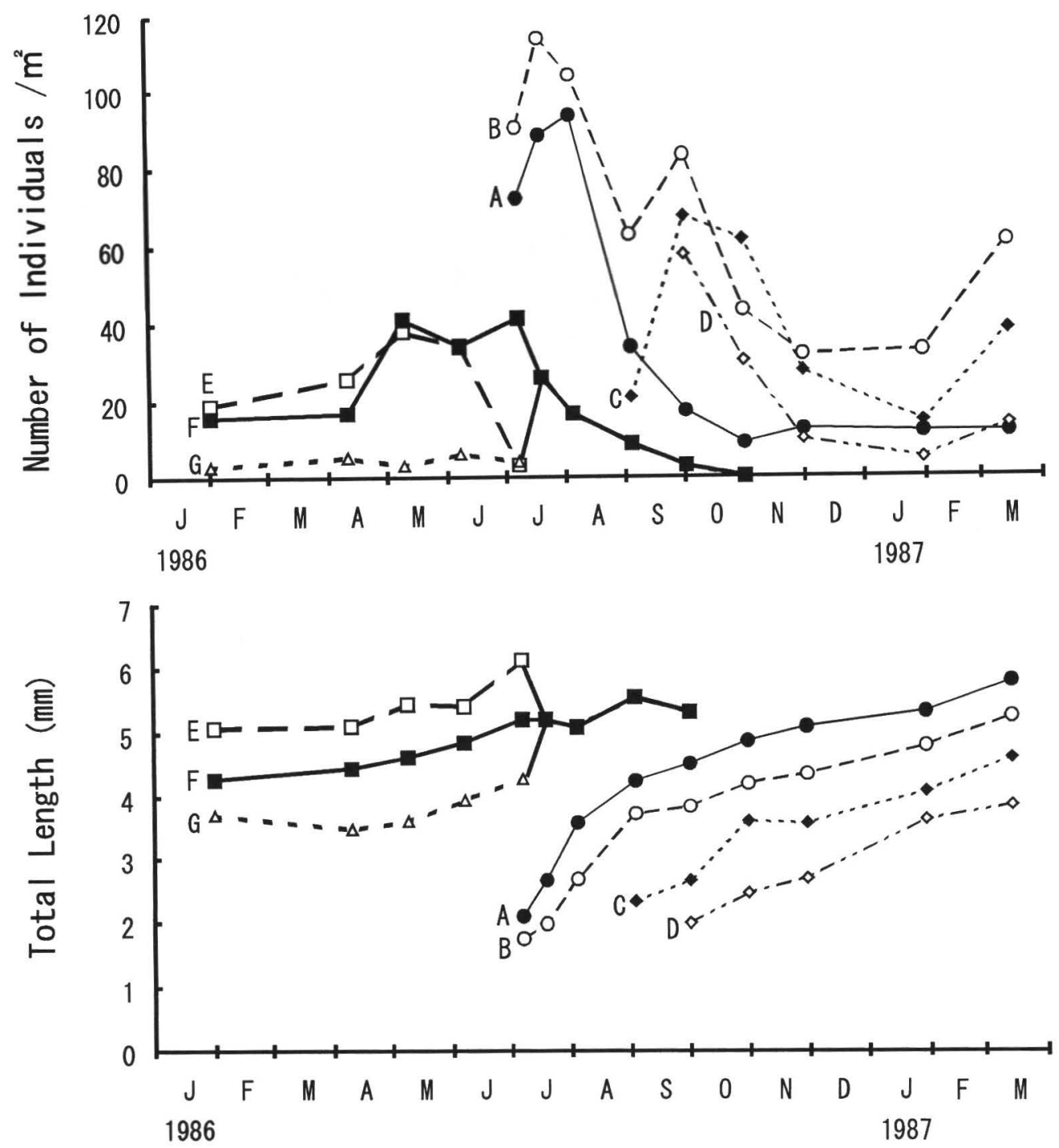

Fig. 7. Survivorship (above) and growth (below) curves for each cohort of females of Eurydice nipponica during the study period, based on the cohort separation in Fig. 3. Cohorts E and G merge into Cohort F on 20 July 1986 (see text).

survivorship and growth curves, respectively for each female cohort. Of the two cohorts of the 1986-summer-recruitment group the density of Cohort A decreased much more than that of Cohort B through their first breeding season in autumn 1986. As to the growth, both cohorts showed a similar pattern, with the rates being higher during the first 2 mo after recruitment and becoming lower subse- quently. The initial high growth rates would have enabled these cohorts' members to mature rapidly. Of the two cohorts of the 1986-autumn-recruitment group the survival rate was higher in Cohort $\mathrm{C}$ than in Cohort D. From 4 September 1986 to 16 March 1987, the growth rates were similar among the four cohorts. As a consequence of the above processes, on 16 March 1987, the dominant components of 
the 1986-recruitment groups were Cohorts B and C, and the TL-modes were ordered successively from Cohort A to Cohort D.

An analysis of the female 1985-recruitment group during 31 January to 8 July 1986 showed that only three normaldistribution groups could be discriminated, designated as Cohorts E, F, and G (from large to small in size) in Fig. 3. No samples had been collected in 1985 to determine the number of recruitment pulses that corresponded to these cohorts. From 20 July to 2 October 1986, the separation of multiple cohorts was impossible, and hence the entire distribution was treated as a single, fused "cohort" (expressed as $\mathrm{E}+\mathrm{F}+\mathrm{G})$. During the earlier breeding season of 1986 (from May to July), the density of Cohort E decreased remarkably, while a high survival rate was maintained in Cohort F (Fig. 7above). The density of Cohort $\mathrm{G}$ remained at a low level throughout. Therefore, during the later breeding season of 1986 (from 20 July to 2 October), the dominant component of the 1985-recruitment group was Cohort F. In each of the three cohorts, growth continued steadily throughout their life span (Fig. 7-below).

\section{Survival and growth in males}

In Fig. 3, the asterisk drawn in the figure on each date indicates the median TL for all male individuals (excluding the juveniles). Following the summer-recruitment in July 1986, male Cohorts A and B had merged into the male 1985-recruitment group as early as 4 September, during which time the body growth in the latter group seems to have almost stopped. In males, therefore, the successive merging of juveniles into the preceding cohorts was expected, so that the examination of the characteristics of survivorship (based on Fig. 6) and growth (Fig. 3) is obliged to cover the male population as a whole throughout the study period. The two cohorts of the 1986-autumn-recruitment group (Cohorts $\mathbf{C}$ and $\mathrm{D}$ ) merged into the preceding cohorts by 1 November 1986 and by 31 January 1987, respectively (Fig. 3). During 5 August 1986 to 16 March 1987, the median TL increased only slightly, from 3.5 to $4.0 \mathrm{~mm}$. The abrupt decrease in density observed from 5 August to 2 October 1986 (Fig. 6) suggests a high mortality in the two cohorts of the 1986-summer-recruitment group, similar to that recorded for female Cohort A (the preceding section). During 31 January to 20 July 1986 , the median TL decreased slightly, from 4.3 to $3.7 \mathrm{~mm}$ (Fig. 3). The density of the male 1985recruitment group on 10 May 1986 had decreased by $31.5 \%$ on 20 July, after which the disappearance process for the group cannot be tracked owing to the fusion with the juveniles (Fig. 6).

\section{Ontogenetic zonation and temporal dynamics}

Figure 8 shows the spatial and temporal changes in densities and zonation of juveniles, males, and females along the tidal gradient. During the first recruitment pulse ( 8 and 20 July 1986: Fig. 3), the center of the distribution of juveniles was around the middle of the transect (Stns 160 and 180), with their densities decreasing in both directions. With growth, juveniles had moved seaward on 5 August and 4 September. In the midst of the second recruitment pulse (2 October), the highest densities of juveniles were again recorded around the middle of the transect (Stns 120, 140, and 180). In November and December, juveniles were widespread over the transect.

Between males and females, the distribution patterns along the transect were mostly similar during the study period. In January and April 1986, the isopods were distributed fairly evenly over the transect. In May and June, when their breeding activity reached the first peak in the year [as evidenced by the increased proportions of females with newly-fertilized eggs (Egg Stage II): Fig. 4], most indi- 


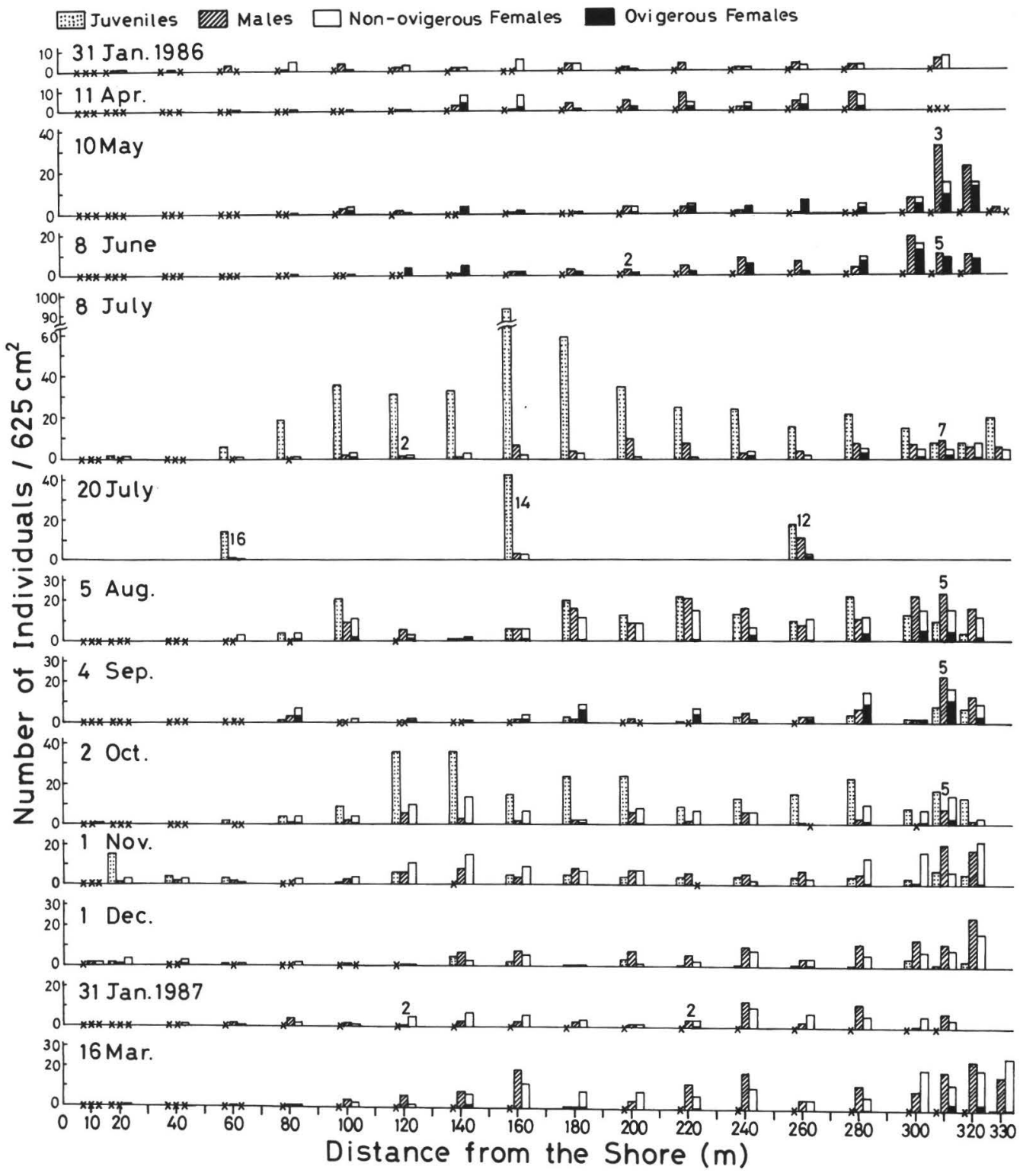

Fig. 8. Spatial and temporal changes in the densities of juveniles (left above each station), males (center), and non-ovigerous plus ovigerous females (right) of Eurydice nipponica along the transect during the study period. Crosses indicate zero values. For the stations where replicate samples were collected (otherwise, one), mean values for each of the above four categories with the numbers of samples are indicated. The cases in which the core (instead of quadrat) sampling was conducted at the lowest three stations owing to temporary submergence (see Materials and Methods) are: (Stns 320 and 330 on 10 May 1986), (Stn 320 on 8 June 1986), (Stns 320 and 330 on 8 July 1986), (Stns 320 on 5 Aug., 4 Sep., 2 Oct., and 1 Nov. 1986), (Stn 310 on 31 Jan. 1987), and (Stn 330 on 16 Mar. 1987). The MLWS level is at Stn 310. The MLWN level is at Stn 160, from which landward the elevation is nearly the same to the shore. 
viduals were located in the seaward half of the transect. In particular, their highest densities around the MLWS level are noteworthy. During July to August, the animals spread widely again, probably reflecting the abundance of the smallest sex-identified individuals located more landward (the preceding paragraph). Meanwhile, the densities of ovigerous females remained the highest in the lower part of the transect. In September, when the breeding activity reached the second peak in the year (Fig. 4), the highest densities of both sexes were again observed around the MLWS level. This pattern continued during October to November, when there were also the other maximum densities around Stns 120 and 140, repeating the abundance pattern of the smallest sex-identified individuals mentioned above. From December 1986 onwards, especially in January 1987, the population was spread out over the transect, especially in January 1987, with the highest densities around the MLWS level recorded in December 1986 and in March 1987.

\section{Discussion}

Possibility of seasonal migration of Eurydice nipponica

Offshore migration of the substantial part of the overwintering population on sandy beaches was recorded for Eurydice pulchra in Arcachon, southwestern France (Salvat, 1966), in southern Wales (Jones \& Naylor, 1970), and in western Wales (Fish, 1970), for $E$. affinis in southern Wales (Jones, 1970), and for E. longicornis in Algoa Bay, South Africa (De Ruyck et al., 1991). For all these cases the authors suggest that the subtidal areas are sought out by the isopods as a shelter against the harsher, intertidal conditions occurring during winter, such as storms and lower temperatures. Since during late autumn to early spring in the present study area, northerly winds causing washing waves were prevailing in contrast to the calmer conditions of the other seasons (Tamaki, 1984, 1987, 1994), the emigration and re-immigration of the population of $E$. nipponica between the intertidal and subtidal areas is likely. This could explain the temporary reduction in the whole density of the overwintering population in the study area (Fig. 6).

Life history pattern of Eurydice nipponica

For females of Eurydice nipponica, the present data set available (Figs. $3,4,7$ ) is not complete to describe in detail their life history pattern, since none of the cohorts were traced throughout from their recruitment to disappearance. To describe the life history, therefore, it is necessary to "synthesize" the data of the 1985- and 1986-recruitment groups and assume that 1) Cohort $E$ was derived from the fusion of the two cohorts of the 1985-summer-recruitment group and 2) Cohorts F and $G$ represent the 1st and 2nd cohorts of the 1985-autumn-recruitment group, respectively. These assumptions would not be unreasonable in the light of the observation of the much higher densities of Cohorts B and C than those of Cohorts A and D on 16 March 1987 (Fig. 7). Based on the above, we interpret the life history pattern for each cohort as follows: 1) the 1st cohort of the summer-recruitment group-subsequent to the recruitment occurring during mid-June to mid-July, the animals grow and mature rapidly to have their first brood in as short as 2 mo, giving birth to either the 1st or the 2nd cohort of the autumn-recruitment group and suffering a considerable reduction in density by the end of November, with the estimated maximum life span for most members being 3-5 mo. Only a small proportion of the cohort could overwinter to join the 2nd cohort of the summer-recruitment group; 2) the 2nd cohort of the summer-recruitment group-subsequent to the recruitment occurring during mid- to late July, the animals show a precocious 
growth and breeding pattern similar to that in 1), giving birth to the 2nd cohort of the autumn-recruitment group, but further, a noticeable number of individuals overwinter to have their second brood in the earlier part of the breeding season of the following year, giving birth to either the 1st or the 2nd cohort of the summerrecruitment group. The significant difference in the clutch size between the first and second broods corrected for female body size in this cohort (Fig. 5) suggests the use of a greater fraction of the internal space for egg-brooding in the largersized females that had overwintered. Only a few members of the cohort, if any, could further survive to participate in the later part of the breeding season, accordingly the maximum life span for most members is estimated as $11-12 \mathrm{mo} ; 3$ ) the 1st cohort of the autumn-recruitment group-subsequent to the recruitment occurring during September, for the first $2 \mathrm{mo}$, the animals grow at a fairly high rate comparable to that in the 2 nd cohort of the summer-recruitment group but have no broods within the year of their recruitment. A noticeable number of individuals overwinter to have their first brood in the earlier part of the breeding season of the following year (but later than in the 2nd summer-recruitment group), giving birth to mainly the 2 nd cohort of the summer-recruitment group. Some members have also the second brood in the later part of the breeding season before their death during October, giving birth to mainly the 1st cohort of the autum-recruitment group. Thus the maximum life span is estimated as 12-13 mo; and 4) the 2nd cohort of the autumnrecruitment group-subsequent to the extended recruitment occurring from the beginning of October to the beginning of November [probably due to the nonphased broodings by the different ovigerous female cohorts referred to in 1)-3) (see Fig. 4)], the population remarkably declines through winter, followed by a quite low density level throughout the ensuing spring and summer. Thus, the life history pattern of the cohort might be similar to that described in 3), but its contribution to the next generations would be minor if at all.

For males of Eurydice nipponica, it is impossible to deduce the life history pattern based only on the body-size frequency distributions because of their much smaller maximum asymptote bodysizes than in females (Fig. 3). There are, however, some suggestions that the survivorship patterns for the summerrecruitment group shortly after its recruitment and for the population occurring during spring to summer were similar to those in females. The slight decrease in the median TL from January to July might be brought about by not only the death of the larger-sized males but also the re-immigration of the smaller-sized males from the subtidal area to the intertidal sandflat. Analysis of histological data of the maturity process, i.e., development of spermatophores (e.g., Jones, 1970; Fish, 1970), might improve the degree of resolution into multiple cohorts.

Comparison with the life histories of the other Eurydice species

Of the beach-dwelling Eurydice species, the life histories have been investigated for three species (cited in Introduction), and a review of the patterns is given in De Ruyck et al. (1991). Of the three species, undoubtedly, the $E$. pulchra population from Arcachon (Salvat, 1966) has characteristics most similar to those of the present $E$. nipponica population. In Arcachon, the seawater temperatures varied from $7.6^{\circ} \mathrm{C}$ (January) to $21.2^{\circ} \mathrm{C}$ (July) in the year [from Fig. 10 in Fish (1970)]. Salvat's (1966) deduction for the pattern, based on the monthly sampling for one year, is summarized as follows, though it is not convincing whether the population is semelparous or iteroparous: 
a) females-1) in February, there were at least two major, discrete cohorts that had overwintered from those recruited during June to August and during September to November, respectively, of the preceding year (hereafter referred to as the preceding summer- and autumn-recruitment cohorts); 2) with growth, those individuals became ovigerous, starting from the larger-sized ones in March, when the seawater temperature had rapidly increased by $3.7^{\circ} \mathrm{C}$ from February; 3) during March to July, ovigerous females underwent the incubation period of 2-3 mo, subsequently giving birth to a new cohort (hereafter referred to as the current summer-recruitment cohort); 4) after the release of the above newly-recruited mancas, a substantial portion of the preceding summer- and autumn-recruitment cohorts died off, especially so for the larger-sized individuals between July and August. Salvat (1966) states that all members of these cohorts died out by mid-August as for males shown in b) below (9-14-mo life span is implied), but the body-length frequency distribution (his Graph. 24) seems to indicate that some smaller-sized individuals further survived until as late as October, during which time they had the second brood with the incubation period of $1 \mathrm{mo}$, giving birth to another new cohort (hereafter referred to as the current autumn-recruitment cohort); 5) as short as 2 mo after their recruitment, the members of the current summerrecruitment cohort rapidly grew and joined the preceding cohorts in terms of not only body dimensions but also the breeding activity during August to October. The ovigerous females in this period were smaller than those during March to July, producing a smaller number (on average, a half) of eggs per female. Although a fair portion of the current summer-recruitment cohort died off during September to November (3-5-mo life span is implied), at least some members overwintered; and 6) the members of the current autumn-recruitment cohort did not become ovigerous until the following breeding season; b) males -the life history pattern was regarded basically the same as in females, although there were some differences in the changing pattern of the body-length frequency distributions: 1) between July and August, the preceding summer- and autumn-recruitment cohorts died out, accordingly in autumn, there was no overlap with the current summer-recruitment cohort. This nonoverlapping pattern is also different from that found for males of E. nipponica; and 2 ) in the overwintering population occurring from December to February, the summer- and autumn-recruitment cohorts were not so discrete from each other as in females, exhibiting a rather continuous body-length frequency distribution. This was due to the smaller maximum asymptote body-sizes of males and the death of the larger-sized members of the current summer-recruitment cohort during summer and autumn. In summary, the life history patterns of both the $E$. nipponica and $E$. pulchra populations can be regarded as modifications of one of the basic patterns commonly observed for smaller-sized crustaceans such as hyppolytid and palaemonid shrimps and amphipods in warm temperate waters, in which there are two generations in the year, recruited during late summer to autumn (the overwintering, long-lived one) and during late spring to early summer (the precocious, short-lived one), respectively [e.g., a review by Kikuchi (1984)].

In southern Wales, which is under cold temperate climatic regimes with seawater temperatures at least $4-5^{\circ} \mathrm{C}$ lower than in Arcachon during the summer months, the Eurydice pulchra population is characterized by a more prolonged growing period to maturity, lacking any precocious cohorts within the year of their recruitment, a shorter breeding season ( 5 mo), and a longer life span (up to $20 \mathrm{mo}$ ) (Jones, 1970). For the E. pulchra popula- 
tion in an estuary of western Wales, where the winter seawater temperatures are distinctly lower and the variation in salinity is greater than in Jones' (1970) study sites, Fish (1970) recorded much more intensified tendencies for the above, with the longest life span of 24 mo. More generally, a similar latitudinal pattern has emerged for shore cirolanid isopods, with the reproductive period increasing from cold-temperate to tropical regions [e.g., see reviews in Shafir \& Field (1980), Zuñiga et al. (1985), and De Ruyck et al. (1991)].

\section{Zonation dynamics of Eurydice nipponica on the sandflat}

Considering endogenous circa-tidal, circadian, and circa-semilunar swimming and burrowing rhythms possessed by a variety of Eurydice species [e.g., a review in Jones \& Hobbins (1985)], the present data taken only in spring tides (Fig. 8) is apparently insufficient for specifying the mechanisms underlying the observed distribution patterns of $E$. nipponica on the sandflat. Nevertheless, some interesting features appear. For $E$. nipponica inhabiting an open beach in Kyushu Island, Jones \& Hobbins (1985) recorded a clear circa-tidal rhythm with swimming activity of 5-6 h centered on high tide and suggested the presence of a circa-semilunar rhythm in determining the distribution along the elevation gradient of the beach. The population there occupied the zone between the MLWN level (= the center of the distribution in a neap tide) and the MLWS level (= the center of the distribution in spring tides), with some individuals extending down into the subtidal zone. This observation is consistent with the distribution pattern of the present $E$. nipponica population, in that 1) the entire intertidal sandflat with its small offshore extension is at the tidal height (= below the MLWN level) which is primarily inhabitable by the isopod and 2) except during January (to early spring), the cen- ter of the distribution of females and males was generally situated around the MLWS level each month. The widespread distribution along the transect during winter (to early spring) might be brought about through the landward transportation of animals by strong incoming waves caused by seasonal, northerly winds, as demonstrated for several other macrobenthic species on the sandflat (Tamaki, 1985, 1987, 1994). Interestingly, in JuneJuly and in September, when the mating activity of $E$. nipponica was supposed to be at its maxima, the intensified tendency for the concentration of both sexes around the MLWS level was observed. Such lower-shore concentration of the breeding components was described for $E$. pulchra in western Wales (Fish, 1970), and there is some suggestion in the distribution pattern for the same species in Arcachon [Graph. 20 in Salvat (1966)]. On the present sandflat, the center of the distribution of the newly-recruited juveniles was about the halfway stations of the transect. Such a spatial pattern in newly settled larvae/juveniles has been commonly observed in numbers of macrobenthic species on the sandflat (Tamaki, 1985, 1987, 1994). Bruce \& Soares (1996) recorded a spatial size-segregation along the tidal gradient for the population of $E$. kensleyi inhabiting a beach on the west coast of South Africa. Presumably, on the present sandflat, the swimming ability of mancas of $E$. nipponica which had just been released from ovigerous females was not strong enough, so that they would have been passively transported and accumulated around those stations through some hydrodynamic processes even during the calm seasons, as suggested for settling larvae/juveniles of the other species (Tamaki, 1985, 1987, 1994). Cannibalism, as demonstrated for $E$. longicornis (De Ruyck et al., 1992), might have been another mechanism generating the zonation by size in the $E$. nipponica population. As the isopod juveniles grew, their increas- 
ing swimming ability would have enabled them to move offshore to the lower tidal zone, especially in the calmer seasons.

The present study was based on the sampling which was limited to the intertidal zone and was conducted only during spring tides with an interval of 2 wk to 2.5 mo for one year. In order to more detail both the life history and the zonation patterns of Eurydice nipponica, the results of the present study and other studies for Eurydice species point to the need for more frequent sampling (e.g., every neap and spring tides) for at least two years over an extended area including some subtidal zone beyond the intertidal zone. Moreover, to reveal yearly variations in the abundance pattern of each of the four cohorts comprising the population, further longer-term data are apparently required. The data could enable us to evaluate the fitness of the members of each cohort, expanding the scope of our study into the life history strategy of the species.

\section{Acknowledgments}

We thank the staff of the Amakusa Marine Biological Laboratory, Kyushu University, for providing facilities. We are also grateful to Mr. I. Goto and Prof. T. Kikuchi for allowing us to use their unpublished data on the water temperature and salinity. Ms. P. Gómez kindly read the Spanish literature for us. The manuscript was improved by comments of Drs. B. Kensley, D. C. Miller, and an anonymous referee.

\section{Literature Cited}

Brown, A. C., \& McLachlan, A., 1990. Ecology of sandy shores. xii $+328 \mathrm{pp}$. Elsevier, Amsterdam.

Bruce, N. L., \& Jones, D. A., 1981. The systematics and ecology of some cirolanid isopods from southern Japan. Journal of Natural History, 15: 67-85.

$\longrightarrow$, \& Soares, A. G., 1996. Taxonomy and ecology of sandy beach Eurydice (Crusta- cea, Isopoda, Cirolanidae) from the West coast of South Africa. Cahiers de Biologie Marine, 37: 77-98.

Cassie, R. M., 1954. Some uses of probability paper in the analysis of size frequency distributions. Australian Journal of Marine and Freshwater Research, 5: 513-522.

Dahl, E., 1952. Some aspects of the ecology and zonation of the fauna on sandy beaches. Oikos, 4: 1-27.

De Ruyck, A. M. C., Donn, T. E., \& McLachlan, A., 1991. Life histories and breeding patterns of three intertidal sand beach isopods. P. S. Z. N. I.: Marine Ecology, 12: 105-121.

——_ \&_, 1992. Distribution of three intertidal cirolanid isopods (Flabellifera: Cirolanidae) on a South African sandy beach. Cahiers de Biologie Marine, 33: 147-168.

Fish, S., 1970. The biology of Eurydice pulchra (Crustacea: Isopoda). Journal of the Marine Biological Association of the United Kingdom, 50: 753-768.

Jones, D. A., 1970. Population densities and breeding in Eurydice pulchra and Eurydice affinis in Britain. Journal of the Marine Biological Association of the United Kingdom, 50: 635-655.

- \& Hobbins, C. S. C., 1985. The rôle of biological rhythms in some sand beach cirolanid Isopoda. Journal of Experimental Marine Biology and Ecology, 93: 47-59. , \& Naylor, E., 1970. The swimming rhythm of the sand beach isopod Eurydice pulchra. Journal of Experimental Marine Biology and Ecology, 4: 188-199.

Kikuchi, T., 1984. Reproductive ecology and life history traits in the marine invertebrates-XII. Introductory notes on life history traits. Kaiyou to Seibutsu (Aquabiology), 6: 285-290. (In Japanese with English abstract)

McLachlan, A., \& Jaramillo, E., 1995. Zonation on sandy beaches. Oceanography and Marine Biology: an Annual Review, 33: 305-335.

Norušis, M. J., 1994. SPSS Advanced Statistics TM 6.1 Manual. xvi + 606 pp., SPSS, Inc., Chicago.

Raffaelli, D., \& Hawkins, S., 1996. Intertidal ecology. $x+356$ pp. Chapman \& Hall, London.

Salvat, B., 1966. Eurydice pulchra-Leach, 1815, Eurydice affinis-H.J. Hansen, 1905 (isopodes Cirolanidae). Taxonomie, ethologie, ecologie, répartition verticale et cycle reproducteur. Actes de la Société 
Linnéenne de Bordeaux (Série A), 103: 1 77.

Shafir,A., \& Field, J. G., 1980. Population dynamics of the isopod Cirolana imposita Barnard in a kelp-bed. Crustaceana, 39: 185-196.

Tamaki, A., 1984. Structural characteristics of an intertidal sand flat in Tomioka Bay, Amakusa, west Kyushu. Publications from the Amakusa Marine Biological Laboratory, Kyushu University, 7: 125-150.

- 1985. Zonation by size in the Armandia sp. (Polychaeta: Opheliidae) population on an intertidal sand flat. $\mathrm{Ma}-$ rine Ecology-Progress Series, 27: 123-133.

, 1987. Comparison of resistivity to transport by wave action in several polychaete species on an intertidal sand flat. Marine Ecology-Progress Series, 37: 181189.

1994. Extinction of the trochid gastropod, Umbonium (Suchium) moniliferum (Lamarck), and associated species on an intertidal sandflat. Researches on Population Ecology, 36: 225-236.

, Ingole, B., Ikebe, K., Muramatsu, K., Taka, M., \& Tanaka, M., 1997. Life history of the ghost shrimp, Callianassa japonica Ortmann (Decapoda: Thalassinidea), on an intertidal sandflat in western Kyushu, Japan. Journal of Experimental Marine Biology and Ecology, 210: 223-250.

\& Suzukawa, K., 1991. Co-occurrence of the cirolanid isopod Eurydice nipponica Bruce \& Jones and the ghost shrimp Callianassa japonica Ortmann on an intertidal sand flat. Ecological Research, 6: 87100.

Taylor, B. J. R., 1965. The analysis of polymodal frequency distributions. Journal of Animal Ecology, 34: 445-452.

Tsutsumi, H., \& Tanaka, M., 1987. A new method for measurement of body size and analysis of generation structure of polychaete populations, using a micro-computer. Benthos Research, 31: 18-27. (In Japanese with English abstract)

Zuñiga, O. R., Peña, R. M., \& Clarke, M. G., 1985. Historia de vida y produccion de Excirolana braziliensis Richardson, 1912 (Isopoda: Cirolanidae). Estudios Oceanologicos, 4: 9-19.

Address: Faculty of Fisheries, Nagasaki University, Bunkyo-machi 1-14, Nagasaki 852, Japan.

E-mail: (AT) tamaki@net.nagasaki-u.ac.jp 